\title{
Recreational fish feeding affects coastal fish behavior and increases frequency of predation on damselfish Chromis chromis nests
}

\author{
Marco Milazzo $^{1, *}$, Isabella Anastasi ${ }^{1}$, Trevor J. Willis ${ }^{2}$ \\ ${ }^{1}$ Dipartimento di Biologia Animale, Università di Palermo, Via Archirafi 18, 90123 Palermo, Italy \\ ${ }^{2}$ Centro Interdipartimentale di Ricerca per le Scienze Ambientali in Ravenna, Università di Bologna, Via S. Alberto 163, \\ 48100 Ravenna, Italy
}

\begin{abstract}
Wildlife feeding has become an integral part of the range of activities offered to protected area visitors. In marine protected areas (MPAs), fish feeding may cause changes in the behavior, and thus the density and distribution, of coastal fish species. We evaluated spatial variability in human-positive fish behavior around the Ustica Island MPA (Italy) and the potential indirect effects of behavioral change on other species. Two mensurative experiments demonstrated that ca. 1/3 of the species present in fish-feeding areas exhibited human-positive behavior, losing instinctive fear in the presence of humans and encircling people in the water even when food was not provided. A manipulative experiment demonstrated that this behavioral response was learned rapidly. Damselfishes were negatively affected by the unnatural aggregation of a labrid species, as these aggregations frequently attacked and destroyed the benthic nests of the damselfish. Thus, fish feeding can have both direct and indirect effects. Therefore the MPA management goals need to be explicitly stated on a case-by-case basis. If the aim of a reserve is only to promote awareness of marine life and the benefits of conservation to the public, activities such as fish feeding may be regarded as desirable, since the human-positive behavior brought about by this activity guarantees a visual spectacle for visitors. Fish-feeding locations, however, cannot be regarded as natural and may reduce the effectiveness of a reserve for scientific research.
\end{abstract}

KEY WORDS: Fish-feeding behavior - Indirect effects - Predation - Marine protected area . Mediterranean · Tourism

\section{INTRODUCTION}

Humans have developed a variety of relationships with animals over the millenia, but it has been only recently that animals, formerly hunted for food or sport, have become objects of tourism in the wild. This change is partly a function of their increasing rarity, and so some of the most rewarding experiences in nature tourism now generally occur within protected areas. Because the funding, and sometimes continued existence, of protected areas often relies substantially on their ability to attract and maintain the support of the public, dynamic interaction with animals is frequently encouraged by management agencies. Active participation reaches its most extreme forms when hand-feeding of otherwise wild animals is conducted as a promotional or commercial exercise (e.g. with tigers, Komodo dragons, squirrels, baboons and macaques) (Huestis 1951a,b, Robinson \& Cowan 1954, McDougal 1980, Manski et al. 1981, Manski 1982, Aggimarangsee 1993, Kamal et al. 1997, Walpole 2001).

The feeding of wild animals by humans has inevitably created a wide range of direct and indirect impacts (Orams 2002). These include health problems in animals caused by the food given and variations in 
species behavior, such as changes in spatial distribution (Huestis 1951a,b), becoming used to the presence of humans (Robinson \& Cowan 1954), alterations in the social structure of animal communities (Manski et al. 1981, Manski 1982) and increases in risk for humans due to potential attacks by the animals (Aggimarangsee 1993, Kamal et al. 1997).

Since 1990 the growing popularity of marine reserves has provided the impetus for the growth of the tourism industry in coastal areas (Davis \& Tisdell 1995, see Milazzo et al. 2002 for a review). This phenomenon has given rise to a number of studies on the effect of feeding activities at sea (e.g. Cole 1994, Orams et al. 1996, Sweatman 1996, Hawkins et al. 1999). Feeding of coastal fishes can cause changes in their spatial distribution by attracting fish to feeding sites (Cole 1994, Sweatman 1996, Hultquist 1997). Habituation to humans may also influence distribution by altering levels of inter- or intraspecific aggression, which may indirectly lead to local changes in assemblage structure.

In the Mediterranean Sea, previous studies carried out in the Ustica Island MPA (southern Italy) demonstrated a clear direct effect of feeding activity by summer tourists on the density and size distribution of some coastal fish species (Milazzo et al. 2005). Since 1991, MPA management has organized guided snorkelling tours in 2 small areas of the no-take zone, with the objective of increasing visitor awareness of marine wildlife. Snorkellers feed fishes with frozen

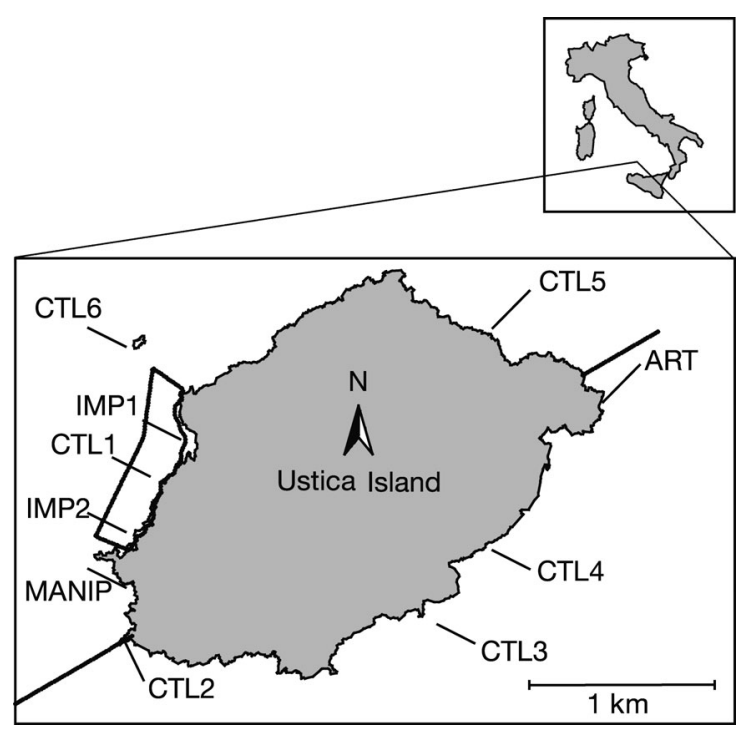

Fig. 1. Ustica Island MPA and sampling locations: Cala Sidoti (IMP1), Cala Acquario (IMP2), Punta Spalmatore (MANIP), Homo morto (ART), Sbarramento (CTL1), Piscina Naturale (CTL2), Punta Galera (CTL3), San Paolo (CTL4), Cala Cimitero (CTL5) and Scoglio del Medico (CTL6) cephalopods and shrimp provided by the MPA staff twice daily. In addition, several times a day a large number of visitors feed the fishes bread in the same locations (M. Milazzo pers. obs.). This activity is absolutely forbidden elsewhere.

In this study our main objectives were to determine whether fish feeding had indirect effects on other components of the assemblage in addition to direct effects on behavior, and whether these had concomitant effects on assemblage structure. Specifically, we examined (1) behavioral changes of fish, (a) evaluating whether, in the presence of snorkellers, fish exhibit a human-oriented behavior causing aggregations around them waiting to be fed, and (b) experimentally evaluating the speed of this response; and (2) indirect effects on other species. For example, we observed attacks by large groups of the labrid Thalassoma pavo on the benthic nests of the pomacentrid Chromis chromis. This stimulated our interest in the potential for unnatural aggregations of fish to increase rates of predation on species that might otherwise be unaffected.

\section{MATERIALS AND METHODS}

Human-oriented behavior. To assess whether feeding alters the behavior of fish in relation to the presence of humans, we compared the approachability (the degree to which fish approach a snorkeller) of fish at 2 locations around Ustica Island (IMP1 and IMP2, Fig. 1), where they are regularly fed, with 6 locations where fish feeding does not occur. Five out of the 6 control locations were popular sites for snorkellers and swimmers (CTL2-CTL6); the 6th was situated inside the no-entry area where human access is strictly forbidden (CTL1) (Fig. 1).

Relative approachability between putative impact and control locations was measured from counts of fish using an inverse fixed point technique. This was a modified version of the standard fixed point (see Harmelin-Vivien et al. 1985 for a review). In each sampling location, the number of fish approaching the diver was counted at 3 min intervals by identifying and counting the number of specimens within a cylinder of $2 \mathrm{~m}$ radius and height (total volume $25 \mathrm{~m}^{3}$ ) having the sea surface as the base and the observer as the central axis. At each of the 8 locations (IMPs and CTLs), 30 replicate counts were performed on different days (ca. $3 \mathrm{~d} \mathrm{wk}^{-1}$, weather permitting) between late June and early September 2001.

If higher fish density increases the likelihood that fish pass close to the observer by chance, differences between locations in the behavioral response of fish to feeding disturbance may be confounded by between- 
location differences in the density and composition of fishes. For this reason, at the beginning of the study, density estimates of fishes at all locations were obtained using 12 replicate $50 \times 5 \mathrm{~m}$ benthic transects conducted by scuba divers at the same locations, and these density estimates were compared with approachability counts.

Differences in approachability of fishes between impacted and control sites were tested using the ANOSIM (analysis of similarities) procedure in the PRIMER package (Clarke \& Warwick 1994), and the species primarily responsible for observed differences were identified using the SIMPER (similarity percentage) procedure (Clarke 1993). Data were square-root transformed to reduce differences in scale among the variables, and Bray-Curtis similarities were used for both analyses.

Behavioral response over time. To estimate the speed with which fishes begin to exhibit diver-positive behavior, we commenced feeding activity at Punta Spalmatore, a location where fish had not been fed previously (MANIP, Fig. 1). In the morning (09:0011:00 h), 2 snorkellers fed fish $2 \mathrm{~kg}$ of bread for $20 \mathrm{~min}$. Experimental feeding was performed on 36 separate days (almost $4 \mathrm{~d}$ per week, weather permitting) between early July and early September 2001. To determine whether fish learned to identify humans with food, fish were also fed at a second location (Homo morto, ART, Fig. 1); however, supplementary food was provided to fish directly from a row boat, when no humans were present in the water. These repeated counts were also carried out in a control location (Punta Galera, CTL3) and in an impacted location (Cala Sidoti, IMP1).

At each of the 4 locations (MANIP, ART, IMP1 and CTL3), 10 replicate approachability counts were performed within four 15 d periods (P1, P2, P3 and P4) from early July to early September 2001. The same 'inverse fixed point' sampling technique described above was employed to evaluate the response of fish to the observer over time. Temporal independence was ensured by performing each census on different days.

Differences among locations, as well as among periods, in the response of the 'disturbed' fish assemblages were tested using 2-way permutational multivariate analysis of variance (PerMANOVA, Anderson 2001) and represented graphically by non-metric multidimensional scaling (nMDS) (Clarke 1993). Data were squareroot transformed to reduce differences in scale among the variables, and BrayCurtis dissimilarities were used for both analyses; p-values in the PerMANOVA were calculated using 9999 unrestricted permutations of the raw data.

Effects of fish aggregations on frequency of Chromis chromis nest predation. The frequency of attacks of Thalassoma pavo on nests of C. chromis was measured in the presence and absence of unnatural aggregations of $T$. pavo to determine if humans were likely to be indirectly responsible for increasing egg mortality of C. chromis. Observations were carried out during 2 separate periods (early July and early August 2001) at 4 locations: Cala Sidoti (feeding location, IMP1), Punta Spalmatore (manipulation location, MANIP), Sbarramento (no-entry location, CTL1) and Piscina naturale (bathing location, CTL2) (Fig. 1). These locations were selected to encompass the full range of human activity and access.

One snorkeller swam along the surface until a Chromis chromis benthic nest was in view (Fig. 2). Once over the nest, unnatural fish aggregations would sometimes form around the snorkeller. When diveroriented behavior of fish occurred, the unnatural fish aggregations formed within 1 to $2 \mathrm{~min}$. When they did not form, the snorkeller waited over the nest for $5 \mathrm{~min}$, and then the observation ceased. A second observer recorded the number of attacks on the nest by Thalassoma pavo (Fig. 2) from an inflatable raft to avoid influencing the response of $T$. pavo to the snorkeller. For analysis, each replicate was the \% frequency of successful attacks on a group of 5 randomly selected nests. This set of 5 observations was replicated $(n=4)$ at each combination of location and sampling time at depths of 6 to $7 \mathrm{~m}$ (Fig. 2). Each observation was made early in the morning (07:30-08:30 h) to avoid sampling when other snorkellers were present in the water.

An attack on a nest was only recorded as positive if the nest was destroyed and subsequently abandoned

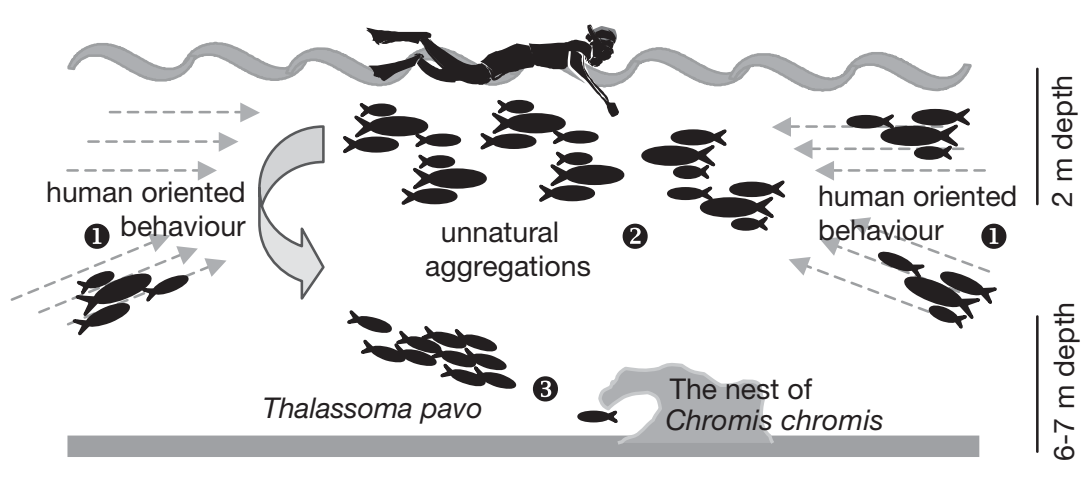

Fig. 2. Sequence of events leading to Chromis chromis egg predation by Thalassoma pavo: (1) human-oriented behavior as a result of fish feeding (e.g. positive behavior), (2) creation of unnatural aggregations of fishes and (3) attack of T. pavo aggregations on C. chromis nest 
by the guarding male Chromis chromis. Where this occurred, the nest was deserted by the male within minutes after the attack. If the nest was attacked but successfully defended, the attack was recorded as negative. Attacks generally lasted 20 to 40 s. New observations were not made on nests previously unsuccessfully attacked by Thalassoma pavo.

Attack frequencies were analyzed using ANOVA with location as a fixed effect and time as a random effect. Homogeneity of variances was tested by the Cochran C-test (Winer 1971). Differences among locations were examined by pairwise SNK (StudentNewman-Keuls) test.
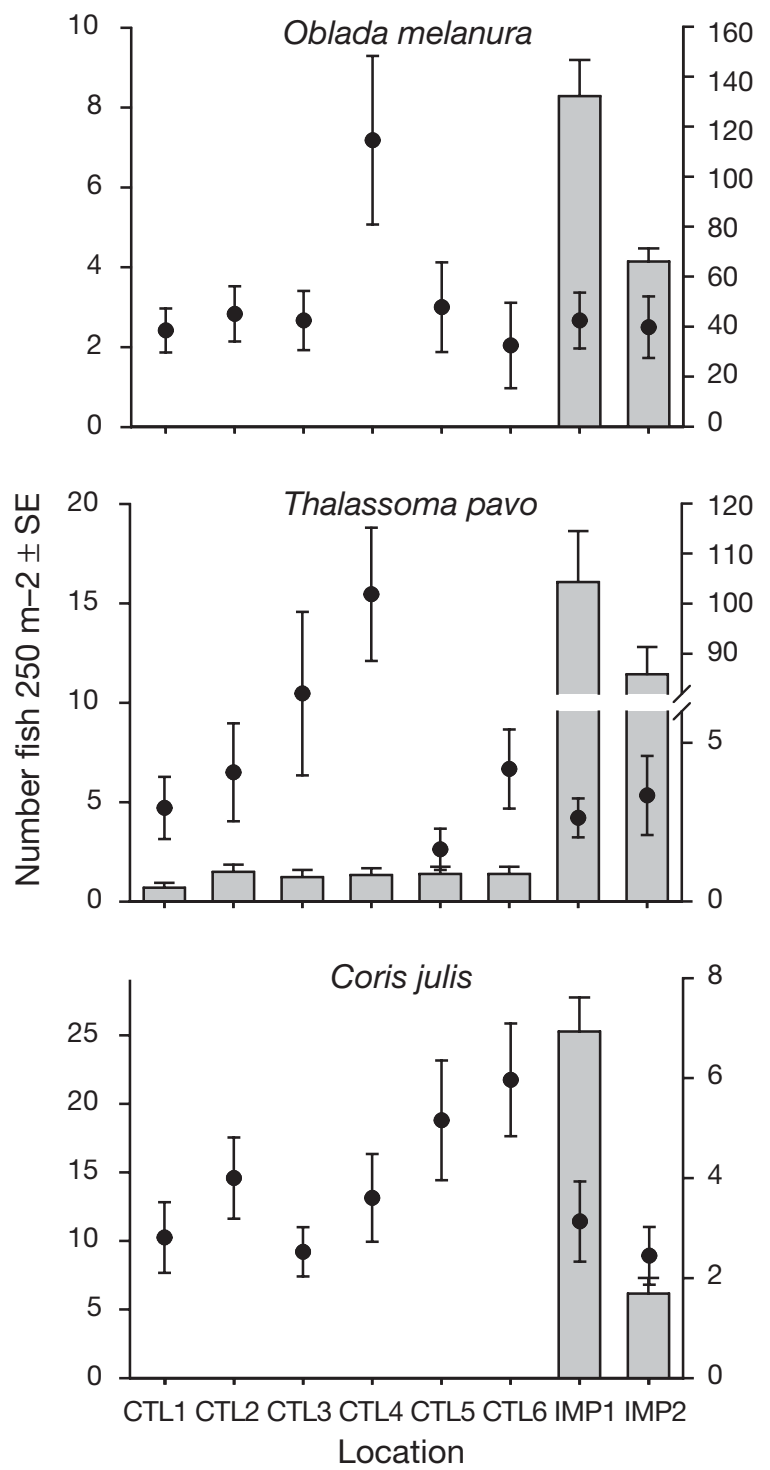

\section{RESULTS}

\section{Human-oriented behavior}

There was a large difference in the approachability of fish between locations where fish were fed and where they were not (ANOSIM, Global $R=0.325$, significance level: $0.1 \%$ ). Twelve taxa exhibited a positive response to humans at feeding sites, whereas very few fish of any species approached snorkellers elsewhere. In the impacted locations, Thalassoma pavo, Coris julis, Chromis chromis, Oblada melanura, Sarpa salpa and Spondyliosoma cantharus reacted
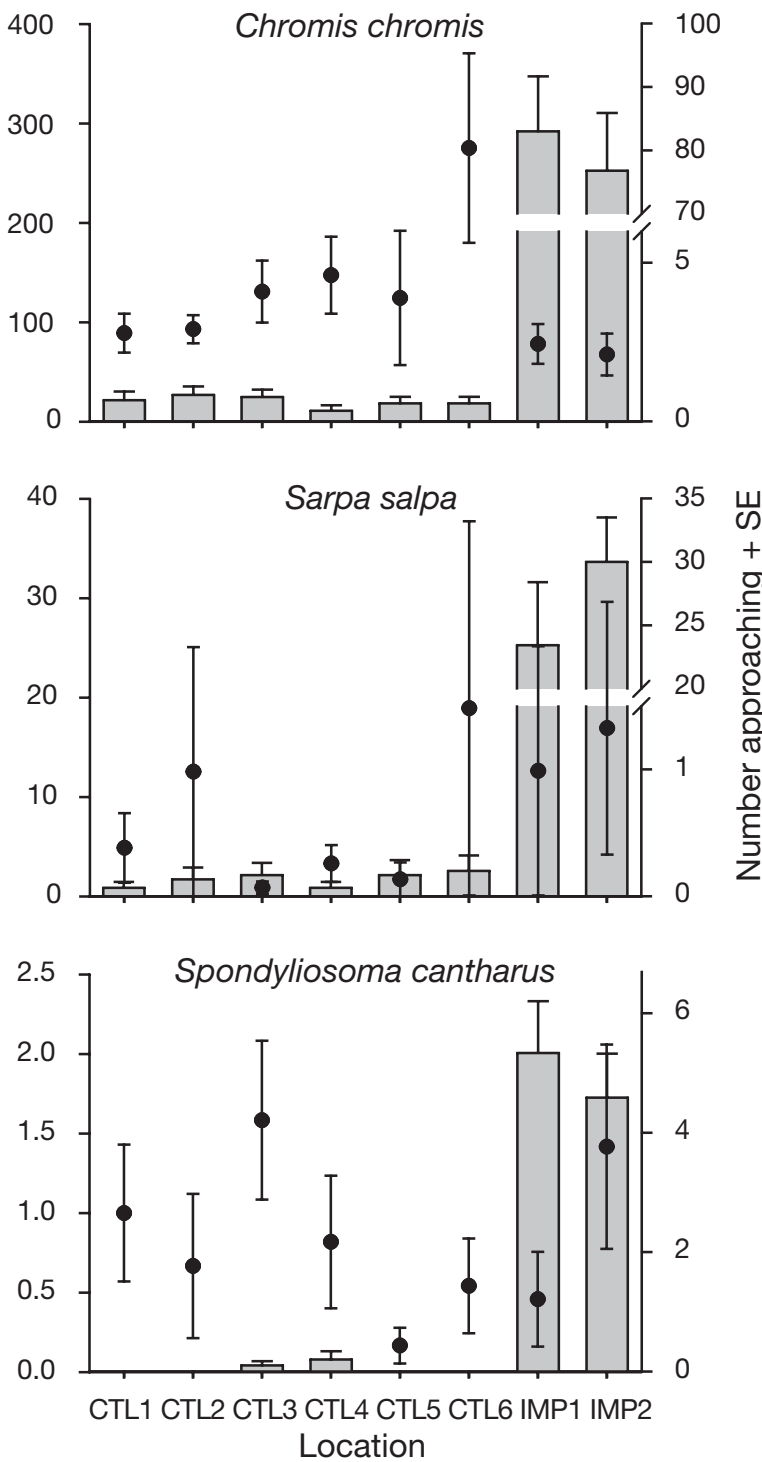

Fig. 3. Comparisons of density estimates (circles \pm SE) and number of fish approaching observer (bars + SE) at impacted (IMP) and control (CTL) study locations for 6 common species. Note: $y$-axis scale varies considerably between plots 
Table 1. Pooled mean count $( \pm \mathrm{SE})$ in impacted and control locations of fish species not used for comparisons in Fig. 3 but approaching humans

\begin{tabular}{|lcc|}
\hline Taxa & $\begin{array}{c}\text { Average number of fish approaching } \\
\text { Impacts } \\
(\mathrm{n}=60)\end{array}$ & $\begin{array}{c}\text { Controls } \\
(\mathrm{n}=180)\end{array}$ \\
\hline Diplodus spp. & $5.1(0.62)$ & - \\
Symphodus ocellatus & $2.4(0.43)$ & $0.02(0.01)$ \\
Mugilidae & $1.6(0.61)$ & - \\
Seriola dumerili & $0.2(0.01)$ & - \\
Epinephelus marginatus & $0.2(0.03)$ & - \\
Boops boops & $0.1(0.02)$ & - \\
\hline
\end{tabular}

strongly to the presence of the observer (Fig. 3). Six other taxa (Epinephelus marginatus, Seriola dumerili, Symphodus ocellatus, Mugilidae, Diplodus spp. and Boops boops) also occasionally approached the observer in the impacted locations (counts ranged from $0.1 \pm 0.02(\mathrm{SE})$ to $5.1 \pm 0.62$ ) but not in control locations (Table 1).

SIMPER analysis showed that Oblada melanura (level of contribution: $23.7 \%)$, Thalassoma pavo $(21.7 \%)$, Chromis chromis $(20.0 \%)$ and Sarpa salpa (11.9\%) contributed most to the dissimilarities between impacted and control locations. The number of fish that approached the observer closely was completely independent of density for any species (Fig. 3); thus the high numbers at impact locations can be attributed to changes in behavior toward humans rather than to an artifact of abundance. Since overall differences in approachability between impacts and controls differed by up to 2 orders of magnitude (Table 1, Fig. 3), whereas densities varied relatively little (Fig. 3), it was unnecessary to standardize approachability counts for density.

\section{Behavioral response over time}

There were large and statistically significant differences among the 4 locations. Only one fish approached the diver at ART over 40 observations, so formal analysis was conducted using the remaining 3 locations (control, impacted and manipulated). The PerMANOVA showed that the main effects of location $(F=46.94, \mathrm{p}<0.01)$ and time period $(F=7.81$, $\mathrm{p}<0.01$ ) were both significant, as was the interaction term $(F=6.25, \mathrm{p}<0.01)$. A posteriori pairwise tests showed that during the first $15 \mathrm{~d}$ period of observations (P1) the composition and structure of the fish assemblages 'disturbed' by experimental feeding (MANIP) did not differ from that of the control location (CTL1, Fig. 4, $t=0.76, \mathrm{p}=0.77$ ) in that there were only a few isolated incidences where individual fish approached the diver (generally Thalassoma pavo or Chromis chromis). In all subsequent time periods, the locations were significantly different from each other (all $t>3.0, \mathrm{p}<0.01$ ), but from P2 onward the fish assemblage of the MANIP location became more similar to that of the impacted location (Fig. 4). The species that contributed most to BrayCurtis dissimilarities among locations and periods were again the gregarious T. pavo, C. chromis, Oblada melanura and Sarpa salpa (SIMPER, Fig. 4). The latter species contributed significantly to group differences because of a stronger positive response to divers at the MANIP site during periods 3 and 4 than occurred at the IMP location.

\section{Effects of fish aggregations on frequency of Chromis chromis nest predation}

At the impacted location (Cala Sidoti, the feeding location) the average frequency of successful attacks by Thalassoma pavo on Chromis chromis nests was $92.5 \%( \pm 10.3 \mathrm{SD})$. In the other locations the frequencies were lower with $60 \%( \pm 15.1 \mathrm{SD})$ at Punta Spalmatore (the manipulation location) and $30 \%( \pm 10.7 \mathrm{SD})$ at Piscina naturale (the bathing zone); there were no attacks at Sbarramento (the no-entry zone) (Fig. 5). The 2-way ANOVA on the frequency (\%) of positive attacks revealed significant differences among the 4 locations $\left(F_{3,24}=70.4 ; \mathrm{p}<0.01\right)$ clearly showing that the frequency of attacks of $T$. pavo that destroyed $C$. chromis nests were proportional to feeding activity intensity and to human presence (SNK test, Fig. 5).

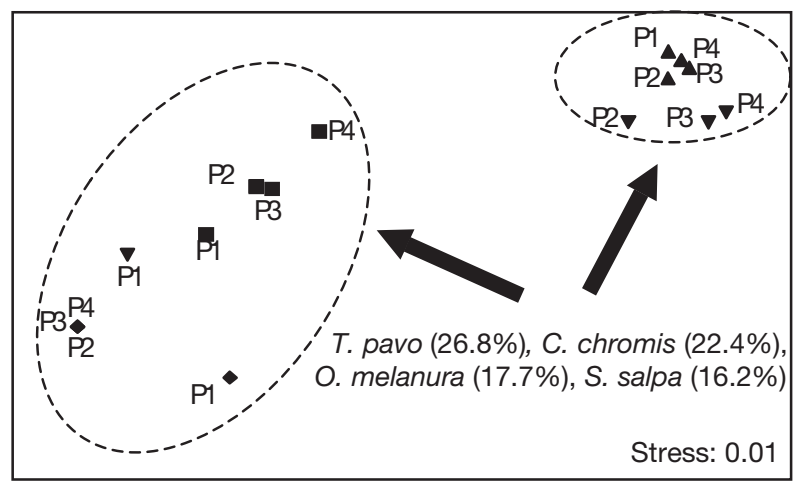

$\triangle$ IMP1 $\nabla$ MANIP $\bullet$ ART $\square$ CTL2

Fig. 4. nMDS ordination (stress $=0.01$ ) of fish assemblages approaching divers over time in 4 fish-feeding treatments: impact (IMP), manipulation (MANIP), artifact (ART) and control (CTL). The different sampling periods were chronologically numbered (P1 to P4). The species contributing most to dissimilarities among the groups and each level of contribution (\%) were reported (SIMPER procedure, cutoff: $75 \%$ ) 


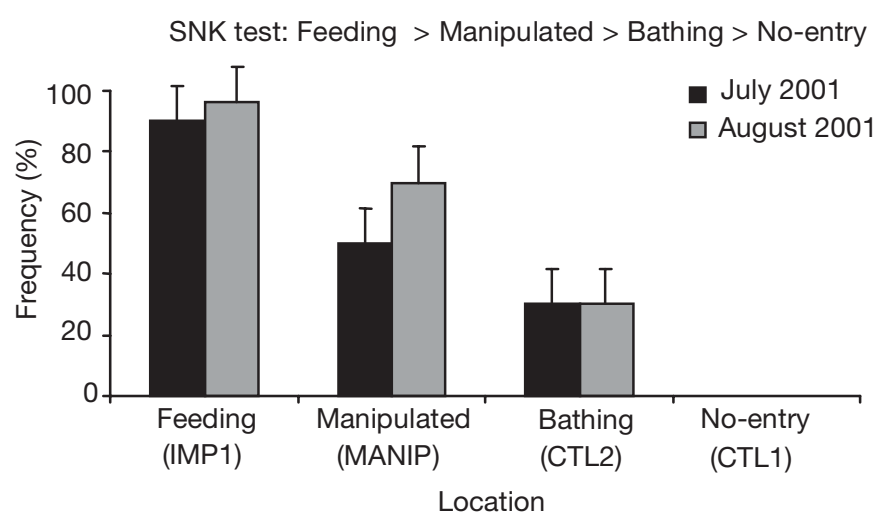

Fig. 5. Average (+SD) frequency (\%) of positive attacks by Thalassoma pavo on Chromis chromis nests between 4 locations with different human uses, at 2 sampling times $(n=4)$. SNK test results for factor location are also reported

\section{DISCUSSION}

Approximately $1 / 3$ of the censused species (12 taxa) in the rocky upper infralittoral of Ustica Island were influenced by feeding activity, causing human-positive behavior. Large differences in the approachability of fishes between locations where fish are fed and where they are not were evident. The extent to which this change in behavior toward humans persists in time is presently unknown.

Approachability values of schooling species could be inflated by chance at localities where fish occur at high densities. However, our results and previous findings (Milazzo et al. 2005) for the same study area revealed that these 2 separate effects of feeding are not necessarily correlated. Density-related bias in approachability counts is not likely to occur in demersal species since approachability counts were done from the surface and fish remaining on the reef were therefore not counted.

The only 2 species - the saddled bream Oblada melanura and the dusky grouper Epinephelus marginatus-whose density increased (e.g. almost tripling) from before to after the feeding season (Milazzo et al. 2005) exhibited different levels of approachability. O. melanura was one of the species driving the differences in fish behavior between control and feeding locations, whereas only a few individuals of E. marginatus approached humans in the feeding locations. Several other abundant (e.g. Thalassoma pavo, Sarpa salpa and Chromis chromis) and rarer species (Spondyliosoma cantharus and Diplodus spp., among others) whose relative density was not affected by the feeding activities (Milazzo et al. 2005), in this study revealed a strong human-oriented behavior, with in some cases tens or hundreds of individuals approaching snorkellers.
Other coastal species such as Apogon imberbis, Atherina spp., Muraena helena and some serranids and labrids, although present in the study area (La Mesa \& Vacchi 1999), were not recorded in our approachability counts. These species do not seem to respond to feeding activities.

The species that did respond to humans were not exclusively macrocarnivores but included normally planktivorous (Chromis chromis) and herbivorous (Sarpa salpa) species. In a New Zealand marine reserve where fish have been fed, Cole (1994) obtained strong human-positive responses from 2 large macrocarnivores, but no microcarnivores. He did, however, also note responses from a planktivore and a herbivore. The similarity of our results suggests that normal feeding mode is not a predictor of the likelihood that a species will respond to feeding.

The speed of response to the initiation of artificial feeding was rapid, particularly for Thalassoma pavo and Chromis chromis, both of which were attracted to divers after only $15 \mathrm{~d}$. An unexpected result was the response of Sarpa salpa after the third feeding period at the manipulated site, which was much stronger than that seen at the impacted location. This was attributable to the relatively high proportion of $S$. salpa juveniles recorded at this location, which tend to be naturally more curious than adults. At IMP1, however, the S. salpa approaching the snorkeller were adults.

These results demonstrate that behavior can be easily altered in many fish species that may be otherwise naturally timid or have learned to actively avoid humans (Jennings \& Polunin 1995, Kulbicki 1998, Willis et al. 2000). The importance of specific cues to reef fishes in initiating learned behavior is demonstrated by the lack of response to snorkellers seen at the ART site, where fish were fed from a row boat. The lack of either the presence of a bather in the water or the sound of an engine gave the fish no specific event that signified the impending arrival of supplementary food.

Aggregations of predatory fishes (particularly Thalassoma pavo) caused by human-positive behavior can potentially have detrimental impacts on the reproductive success of nesting damselfish, at least on local scales. It is unclear whether the mechanism causing the increase in frequency of attacks on Chromis chromis nests is caused by increased aggression in T. pavo due to the nearby presence of conspecifics or by competitiveness due to the expected arrival of supplementary food, or whether the presence of high numbers of predators overtaxes the ability of the guarding male C. chromis to defend its nest. We note here that $C$. chromis did not respond to feeding when nest guarding, so feeding did not directly lessen the defense of the benthic nests. 
Natural predation by wrasses on damselfish nests has been recorded elsewhere, such as by Thalassoma bifasciatum on the demersal eggs of the Caribbean damselfish Stegastes leucostictus (Izkowitz 1990, Haley \& Miller 2002). This behavior has been recorded in the Mediterranean Sea (Tortonese 1975), although a human-mediated component of predation success has never been noted. Similar events have been observed in New Zealand at locations where fish are frequently fed by divers (e.g. Nursery Cove, Poor Knights Islands), which causes aggregations of the wrasses Coris sandageri and Notolabrus fucicola. Relatively minor disturbances of the substratum by a diver can provoke a rapid attack by groups of up to 40 individuals on nests of Chromis dispilus (T. J. Willis pers. obs.).

There was an unexpectedly high number of successful attacks on Chromis chromis nests by Thalassoma pavo in the bathing zone, where fish feeding is forbidden. Since no change in the behavior of fish in response to snorkellers was recorded in this location, supplementary food is probably not provided illegally by MPA visitors. In the location where human access is not permitted (no-entry zone), no positive attacks were recorded, indicating that human presence alone may explain the difference in attack frequency. It is possible that the presence of high numbers of bathers may temporarily displace C. chromis from their nests sufficiently for $T$. pavo to utilise egg masses as a source of food more regularly than in the absence of bathers. This is unlikely to be due to direct disturbance of the substratum, since all nests studied were in water 6 to $7 \mathrm{~m}$ deep, but it is possible that guarding C. chromis are threatened by the presence of large objects that could be potential predators. This perceived threat may diminish the nest defense of $C$. chromis or cause C. chromis to exhibit signs of stress that encourage $T$. pavo to attack the nest. Consequently, the T. pavo that are resident in bathing zones may have learned to exploit C. chromis nests as a regular food source rather than as an opportunistic supplement, as generally occurs (Tortonese 1975).

The behavior of fish can be altered either negatively, with fish avoiding humans where they are exploited (Jennings \& Polunin 1995, Kulbicki 1998), or positively, with fish aggregating in places where supplementary food is provided by humans (Cole 1994, Milazzo et al. 2005). In our study, as a consequence of recreational feeding, many coastal fish species showed a human-positive behavior. This may have severe effects on the 'disturbed' fish themselves (e.g. making them vulnerable to fishing outside the no-take zone) or on their prey (e.g. as a result of an increased predation success).

The management goals of marine protected areas need to be explicitly stated on a case-by-case basis. If the only purpose of an MPA is to promote awareness of marine conservation to the public, activities such as fish feeding may be regarded as desirable, since the strong human-positive behavior brought about by these activities guarantees a visual spectacle for visitors that cannot generally be found outside MPAs. It should, however, be acknowledged that areas impacted by tourism are no longer natural, and while activities like fish feeding provide good public relations opportunities, they do not necessarily fulfill conservation goals, and they devalue the usefulness of an MPA for research (Cole 1994, Willis et al. 2000, Willis \& Millar 2005). Effective management will seek to limit such activities to specified areas such that human impacts are not felt throughout an entire MPA.

Acknowledgements. We thank the referees and F. Badalamenti (CNR-IAMC, Castellammare del Golfo) for their helpful suggestions on improving this manuscript; R. Camarda and R. Gorgone (University of Palermo) for invaluable help during field work; and A. Himes (CNR-IAMC, Castellammare del Golfo) for her kind contribution. Special thanks are due to D. Bilello, G. Caminita, T. Licciardi, G. Lo Schiavo and M. C. Natale (MPA staff). This study was supported by a grant from the Ministero dell'Istruzione Università e Ricerca (M.I.U.R., Progetto Giovani Ricercatori) to M. M. and is part of his $\mathrm{PhD}$ thesis.

\section{LITERATURE CITED}

Aggimarangsee N (1993) Survey for semi-tame colonies of macaques in Thailand. Nat Hist Bull Siam Soc 40:103-166

Anderson MJ (2001) A new method for non-parametric multivariate analysis of variance. Austral Ecol 26:32-46

Clarke KR (1993) Non-parametric multivariate analyses of changes in community structure. Aust J Ecol 18:117-143

Clarke KR, Warwick RM (1994) Change in marine communities: an approach to statistical analysis and interpretation. Plymouth Marine Laboratory, Plymouth

Cole RG (1994) Abundance, size structure, and diver-oriented behavior of three large benthic carnivorous fishes in a marine reserve in Northeastern New Zealand. Biol Conserv 70:93-99

Davis D, Tisdell C (1995) Recreational scuba diving and carrying capacity in marine protected areas. Ocean Coast Manage 26:19-40

Haley MP, Müller CR (2002) Territorial behavior of beaugregory damselfish (Stegastes leucostictus) in response to egg predators. J Exp Mar Biol Ecol 273:151-159

Harmelin-Vivien ML, Harmelin JG, Chauvet C, Duval C and 7 others (1985) Evaluation visuelle des peuplements et populations de poissons: méthodes et problèmes. Rev Ecol (Terre Vie) 40:468-539

Hawkins JP, Roberts CM, Van't Hof T, De Meyer K, Tratalos J Aldam C (1999) Effects of recreational scuba diving on Caribbean coral and fish communities. Conserv Biol 13: 888-897

Huestis RR (1951a) The golden-mantled squirrels in Crater Lake National Park. Crater Lake Nat Notes 1:5-15

Huestis RR (1951b) Report on the trapping and marking of golden-mantled squirrels at Crater Lake National Park, 1939. Crater Lake Nat Notes 1:16-22 
Hultquist JR (1997) Effects of fish feeding on a coral reef. Technical report, Hawai'i Sea Grant Program, Hilo

Izkowitz M (1990) Heterospecific intruders, territorial defense and reproductive success in the beaugregory damselfish. J Exp Mar Biol Ecol 140:49-59

Jennings S, Polunin NVC (1995) Biased underwater visual census biomass estimates for target-species in tropical reef fisheries. J Fish Biol 47:733-736

Kamal KB, Boug A, Brain PF (1997) Effects of food provisioning on the behavior of commensal Hamadryas baboons, Papio hamadryas, at Al Hada Mountain in western Saudi Arabia. Zool Middle East 14:11-22

Kulbicki M (1998) How the acquired behavior of commercial reef fishes may influence the results obtained from visual censuses. J Exp Mar Biol Ecol 222:11-30

La Mesa G, Vacchi M (1999) An analysis of the coastal fish assemblage of the Ustica Island Marine Reserve (Mediterranean Sea). PSZN I: Mar Ecol 20:147-165

Manski DA (1982) Management of grey squirrels and people in a downtown national park. Park Sci 2:8-9

Manski DA, VanDruff LW, Flyger V (1981) Activities of grey squirrels and people in a downtown Washington, DC park: management implications. In: Proceedings of the 46th North American Wildlife and Natural Resources Conference 46:439-454

McDougal C (1980) Some observations on tiger behavior in the context of baiting. J Bombay Nat Hist Soc 77:476-485

Milazzo M, Chemello R, Badalamenti F, Camarda R, Raggio S (2002) The impact of human recreational activities in marine protected areas: What lessons should be learnt in

Editorial responsibility: Otto Kinne (Editor-in-Chief), Oldendorf/Luhe, Germany the Mediterranean sea? PSZN I: Mar Ecol 5(Suppl 1): $280-290$

Milazzo M, Badalamenti F, Vega Fernandez T, Chemello R (2005) Effects of fish feeding by snorkellers on the density and size distribution of fishes in a Mediterranean marine protected area. Mar Biol 146:1213-1222

Orams MB (2002) Feeding wildlife as a tourism attraction: a review of issues and impacts. Tour Manage 23:281-293

Orams MB, Hill GJE, Baglioni AJ (1996) 'Pushy' behavior in a wild dolphin feeding program at Tangalooma, Australia. Mar Mammal Sci 12:107-117

Robinson DJ, Cowan IM (1954) An introduced population of the grey squirrel (Sciurius carolinensis Gmelin) in British Columbia. Can J Zool 32:261-282

Sweatman HPA (1996) Impact of tourist pontoons on fish assemblages on the Great Barrier Reef. CRC Reef Research Centre, Townsville, Queensland

Tortonese E (1975) Osteichthyes (Pesci Ossei), Vol II. Fauna d'Italia. Calderini, Bologna

Walpole MJ (2001) Feeding dragons in Komodo National Park: a tourism tool with conservation complications. Anim Conserv 4:67-73

Willis TJ, Millar RB (2005) Using marine reserves to estimate fishing mortality. Ecol Lett 8:47-52

Willis TJ, Millar RB, Babcock RC (2000) Detection of spatial variability in relative density of fishes: comparison of visual census, angling, and baited underwater video. Mar Ecol Prog Ser 198:249-260

Winer BJ (1971) Statistical principles in experimental design. McGraw-Hill, Tokyo

Submitted: March 3, 2005; Accepted: September 19, 2005 Proofs received from author(s): February 21, 2006 